ERRATUM OPEN

\title{
Erratum: Variable frequency of LRRK2 variants in the Latin American research consortium on the genetics of Parkinson's disease (LARGE-PD), a case of ancestry
}

Mario Cornejo-Olivas ${ }^{1,2}$, Luis Torres ${ }^{3,4}$, Mario R. Velit-Salazar ${ }^{1,5}$, Miguel Inca-Martinez ${ }^{1}$, Pilar Mazzetti ${ }^{1,4}$, Carlos Cosentino ${ }^{3,4}$, Federico Micheli ${ }^{6}$, Claudia Perandones ${ }^{6}$, Elena Dieguez ${ }^{7}$, Victor Raggio ${ }^{8}$, Vitor Tumas ${ }^{9}$, Vanderci Borges ${ }^{10}$, Henrique B. Ferraz $\mathbb{D}^{10}{ }^{10}$ Carlos R. M. Rieder $\mathbb{D}^{11}{ }^{1}$, Artur Shumacher-Schuh ${ }^{11}$, Carlos Velez-Pardo ${ }^{12}$, Marlene Jimenez-Del-Rio ${ }^{12}$, Francisco Lopera ${ }^{12}$, Jorge Chang-Castello ${ }^{13}$, Brennie Andreé-Munoz ${ }^{14}$, Sarah Waldherr ${ }^{15,16}$, Dora Yearout ${ }^{15,16}$, Cyrus P. Zabetian ${ }^{15,16}$ and Ignacio F. Mata $^{15,16}$ npj Parkinson's Disease (2018)4:3 ; doi:10.1038/s41531-017-0025-1

Erratum to: npj Parkinson's Disease (2017); doi:10.1038/s41531017-0020-6; Published online 02 June 2017

The original version of this article contained an error in the name of gene $L R R K 2$, which was incorrectly given as Leucine Repeat Rich Kinase 2. The correct name is Leucine Rich Repeat Kinase 2. This has now been corrected in the HTML and PDF versions of this Article.

Open Access This article is licensed under a Creative Commons Attribution 4.0 International License, which permits use, sharing, adaptation, distribution and reproduction in any medium or format, as long as you give appropriate credit to the original author(s) and the source, provide a link to the Creative Commons license, and indicate if changes were made. The images or other third party material in this article are included in the article's Creative Commons license, unless indicated otherwise in a credit line to the material. If material is not included in the article's Creative Commons license and your intended use is not permitted by statutory regulation or exceeds the permitted use, you will need to obtain permission directly from the copyright holder. To view a copy of this license, visit http://creativecommons. org/licenses/by/4.0/.

(c) The Author(s) 2018

\footnotetext{
${ }^{1}$ Neurogenetics Research Center, Instituto Nacional de Ciencias Neurologicas, Lima, Peru; ${ }^{2}$ Northern Pacific Global Health Research Training Consortium, Bethesda, MD, USA; ${ }^{3}$ Movement Disorders Unit, Instituto Nacional de Ciencias Neurologicas, Lima, Peru; ${ }^{4}$ Universidad Nacional Mayor de San Marcos, Lima, Peru; ${ }^{5}$ Universidad Peruana Cayetano Heredia, Lima, Peru; ${ }^{6}$ Hospital de Clínicas José de San Martín, Universidad de Buenos Aires, Buenos Aires, Argentina; ${ }^{7}$ Neurology Institute, Universidad de la Republica, Montevideo, Uruguay; ${ }^{8}$ Department of Genetics, Facultad de Medicina, Universidad de la Republica, Montevideo, Uruguay; ${ }^{9}$ Ribeirão Preto Medical School, Universidade de São Paulo, Ribeirão Preto, Brazil; ${ }^{10}$ Movement Disorders Unit, Department of Neurology and Neurosurgery, Universidade Federal de São Paulo, São Paulo, SP, Brazil; ${ }^{11}$ Hospital de Clínicas de Porto Alegre, Porto Alegre, Brazil; ${ }^{12}$ Neruroscience Research Group, Medical Research Institute, Universidad de Antioquia, Medellin, Colombia; ${ }^{13}$ Department of

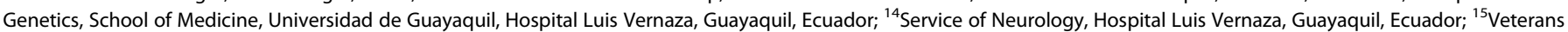
Affairs Puget Sound Health Care System, University of Washington, Seattle, WA, USA and ${ }^{16}$ Department of Neurology, University of Washington, Seattle, WA, USA
} Correspondence: Ignacio F. Mata (nachofm@uw.edu)

Published online: 19 January 2018 